\title{
Actualización: \\ Pubertad precoz y temprana: evaluación y tratamiento
}

Early puberty: evaluation and treatment

Francisco Peper*

\begin{abstract}
Resumen
El autor de este artículo repasa las características clínicas de la pubertad precoz y la pubertad temprana, las pruebas diagnósticas indicadas en la evaluación de los pacientes que la presentan y las recomendaciones actuales de tratamiento.
\end{abstract}

\section{Abstract}

The author of this article reviews the clinical features of early puberty, the diagnostic tests for the patients' evaluation and the current treatment recommendations.

Peper F. Pubertad precoz y temprana: evaluación y tratamiento. Evid Act Pract Ambul 2016;19(4):122-123.

\section{Definiciones}

En la mayoría de las poblaciones, la edad promedio del comienzo de la pubertad es a partir de los diez años para las mujeres y de los 11 para los varones, con un desvío estándar de un año aproximadamente . En las mujeres, el desarrollo comienza con la telarca y la presencia de vello púbico, y en los varones, con el aumento del tamaño de los testículos y del pene. Estos cambios corresponden al estadio Tanner 2.

Se considera pubertad temprana a la aparición de los caracteres sexuales secundarios (Tanner 2), generalmente entre los ocho y los diez años en las mujeres, y entre los 9 y los once en los varones. Se considera pubertad precoz a la ocurrencia antes de los ocho años en mujeres y de los nueve años en los varones.

La pubertad precoz ocurre en aproximadamente 1 a 2 de cada 10.000 personas, y es extremadamente más frecuente en mujeres (una relación $20: 1)^{2}$. Puede ser consecutiva a una variabilidad normal del desarrollo, o bien a alguna condición patológica, y se caracteriza por una rápida maduración ósea, que termina produciendo una baja talla final.

\section{La pubertad precoz puede clasificarse en tres grupos:}

1) Pubertad precoz central (dependiente de gonadotrofina 0 verdadera), causada por la maduración temprana del eje hipotálamo-pituitario-gonadal y caracterizada por una secuencia de maduración normal y ca-racteres sexuales acorde al sexo. En el 40 al $75 \%$ de los varones y en el 10 al $20 \%$ de las mujeres se identifica una causa que explica la afección del sistema nervioso central (SNC). La más frecuente es el hamartoma hipotalámico, seguida por otros tumores como astrocitomas, ependimomas, lesiones por radiación, hidrocefalia, meningocele o causas raras como mutaciones genéticas. En la mayoría (90\%) de los casos no se encuentra una causa clara, definiéndosela, entonces, como pubertad precoz central idiopática.

2) Pubertad precoz periférica (gonadotrofina independiente), causada por la secreción excesiva de estrógenos 0 andrógenos provenientes de las gónadas o de la glándula suprarrenal, de fuentes exógenas de hormonas esteroideas o de la producción ectópica de gonadotropinas por parte de tumores de células germinales. Esta condición puede causar virilización en las mujeres o feminización en los varones.

3) Pubertad precoz benigna o no progresiva, caracterizada por desarro-llo mamario incipiente aislado en mujeres, y/o caracteres sexuales androgénicos incipientes (vello púbico, axilar, acné) en las mujeres y los varones, con ausencia de otros caracteres sexuales secundarios y con velocidad de crecimiento y edad ósea acordes a la edad. Esta condición se debe a la activación temprana del eje hipotálamo-pituitario-gonadal (confirmada mediante la elevación de los niveles de sulfato-dehidroepiandrosterona) y se diferencia de la pubertad precoz central idiopática porno ser progresiva. Esto significa que los signos de desa-rrollo precoz permanecen incipientes y sin progresar, y que el desarrollo "real" sobreviene en una edad promedio.

\section{Evaluación}

La mayoría de las guías no recomiendan estudiar a los niños con pubertad temprana pero la pubertad precoz es una entidad que amerita evaluación ${ }^{3}$. La preocupación y la extensión de la evaluación deberían ser mayores a menores edades de la presentación.

Se debe indagar cuándo aparecieron los cambios puberales, por la presencia de cefalea, cambios en el comportamiento o en la visión, convulsiones o dolor abdominal, historia previa de enfermedad del sistema nervioso central (SNC) o trauma, y/o exposición a esteroides exógenos. También es importante indagar la edad de inicio puberal de los padres y hermanos.

El examen físico debe incluir peso, altura y desarrollo de los caracteres sexuales mediante la escala de Tanner. Si es posible, es útil conocer la velocidad de crecimiento. Los estudios complementarios que deberían solicitarse son:

1) Radiografía de ambas muñecas con informe de la edad ósea. Una edad ósea mayor a dos desvíos estándar respecto de la edad cronológica es indicativa de una pubertad precoz de causa central o periférica y en principio, descarta una variante benigna (aunque tampoco la excluye).

2) En el laboratorio se solicita inicialmente la medición basal de hormona luteinizante (LH), y Folículo estimulante (FSH) y estradiol en las mujeres, y de testosterona en los varones.

3) Se recomienda realizar una Resonancia Magnética Nuclear (RMN) de cerebro con contraste a los menores de seis años por la alta frecuencia de anormalidades en el SNC en este grupo.

La edad ósea acorde a la edad generalmente indica una variable benigna y es, tal vez, el estudio más importante que puede solicitar el médico generalista para separar las aguas y poder dar un pronóstico a la familia. Cuando la edad ósea no es acorde a la edad, esto implica que estamos frente a una pubertad precoz central o periférica. El estudio de estos pacientes es de resorte exclusivo del especialista. Igualmente, debido a que la interpretación de la edad ósea y el manejo clínico de los niños con pubertad precoz no son del todo sencillos, en la mayoría de los casos el médico generalista o el pediatra realiza una consulta con el especialista en endocrinología infantil.

Más allá de las disquisiciones actuales en relación con el tratamiento, el principal objetivo del médico debería ser el de diagnosticar una enfermedad que pueda estar causando la pubertad precoz, que pueda poner en peligro la vida del niño y cuyo tratamiento pueda mejorar el pronóstico. Estamos hablando aquí básicamente de tumores como el hamartoma hipotalámico, que es la causa más frecuente de pubertad precoz central no idiopática, otros tumores del SNC o las raras causas que producen pubertad precoz periférica como los tumores gonadales y adrenales, el síndrome de McCune Albright o la hiperplasia adrenal congénita. 


\section{Tratamiento}

En la pubertad precoz central de causa patológica y en la pubertad precoz periférica, el tratamiento está dirigido a corregir la causa ${ }^{4}$. La pubertad precoz central de causa idiopática no representa, en sí misma, un problema de salud que genere un riesgo para la vida, pero sí determina que estos niños tengan una baja talla final. Lo que ocurre es que el desarrollo puberal acelerado no le da tiempo al hueso a crecer del mismo modo que en la pubertad normal ya que todo el desarrollo ocurre muy rápidamente y el cartílago de crecimiento se cierra precozmente. Actualmente, contamos con un tratamiento eficaz para enlentecer el desarrollo puberal en estos niños: la aplicación exógena continua de agonistas de las hormonas liberadoras de gonadotrofinas que, a diferencia de la pulsátil que ocurre en la pubertad, determina una desensibilización de las células gonadotróficas y una menor producción de hormonas sexuales.

Si este tratamiento se inicia precozmente puede retrasarse el desarrollo puberal y estos niños pueden alcanzar una talla normal para su potencial genético. La decisión de tratarlos dependerá de ciertas variables que evaluará el especialista en forma conjunta con los padres y el niño. Básicamente, cuanto más precozmente se instaure el tratamiento más eficaz será para llegar a una mayor talla ya que si la maduración ósea previa es importante, este no será eficaz. La ganancia de talla debida al tratamiento varía entre 4 y $10 \mathrm{~cm}$, dependiendo del sexo y del momento en el que se instaure.
Considerando que la pubertad precoz central idiopática representa aproximadamente el $90 \%$ de todos los casos (sin incluir aquí la pubertad temprana), podríamos decir que la mayoría de los tratamientos instaurados serían, de alguna manera, "estéticos" (o culturales) ya que no apuntan a resolver un problema serio de salud (como un tumor) sino una menor talla y los problemas sociales y culturales asociados.

Cuando hablamos de tratamientos estéticos (o culturales), y sobre todo en relación con los niños, aparecen disquisiciones morales complejas para los médicos. En la práctica actual, las consultas por pubertad temprana (mucho más frecuente que la pubertad precoz) determina una presión de los padres y de los niños para utilizar el tratamiento disponible (los agonistas de las hormonas liberadoras de gonadotrofinas) para retrasar la pubertad y, tal vez, aumentar ligeramente la talla final. Algunos especialistas denominan a estos tratamientos hormonales (junto a la hormona de crecimiento para aumentar la talla en los niños con baja talla) con el neologismo "endocosmética", término que en sí mismo sugiere controversias morales aun no resueltas por la literatura científica. Es en estos casos donde cobra más valor la toma de decisiones compartidas que requiere por parte del médico una escucha despojada de una mirada moral, ofreciendo con claridad los conocimientos disponibles hasta el momento.

Referencias

1. Lidia Castro-Feijóo M y col. Pubertad precoz. An Pediatr Contin. 2006;4:79-87 - Vol. 4 Núm 2.

2. Midyett $L$ y col. Etiology of central precocious puberty in males: the results of the Italian Study Group for Physiopathology of Puberty, Pediatrics. 2003:111(1):47. 3. Boepple P y col. Precocious puberty. In: Reproductive Endocrinology, Surgery, and Technology, Adashi EY, Rock JA, Rosenwaks Z (Eds), Lippincott-Raven, Philadelphia 1996.

4. Soriano-Guilléna L y col. Pubertad precoz central: aspectos epidemiológicos, etiológicos y diagnóstico-terapéuticos. An Pediatr (Barc). 2011;74(5):336.e1-336.e13

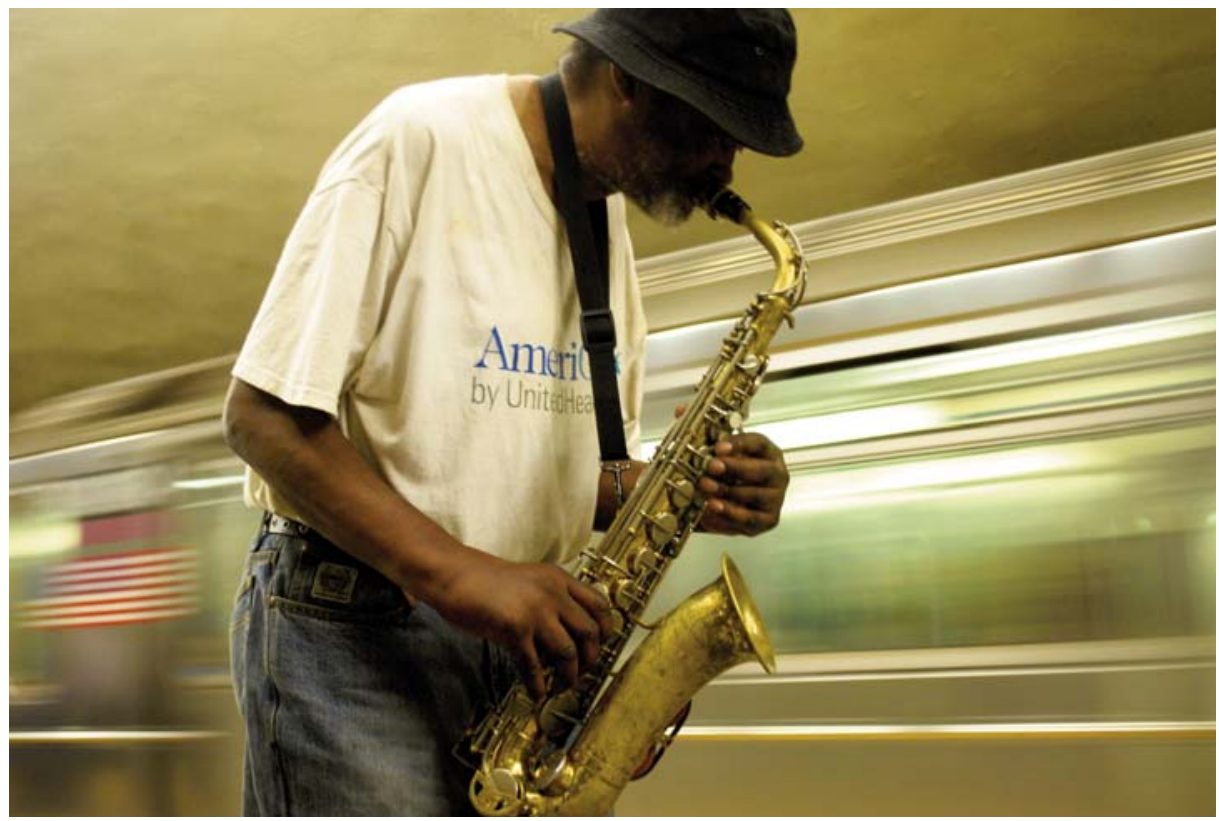

Cortesía: Silvia Spina 